\title{
PERBEDAAN PENGETAHUAN GIZI, POLA MAKAN, DAN KONTROL GLUKOSA DARAH PADA ANGGOTA ORGANISASI PENYANDANG DIABETES MELITUS DAN NON ANGGOTA
}

\author{
Paramita Wahyu Andhika Sari, Muflihah Isnawati* \\ Program Studi Ilmu Gizi Fakultas Kedokteran Universitas Diponegoro \\ Jl.Dr.Sutomo No.18, Semarang, Telp (024) 8453708, Email : gizifk@ undip.ac.id
}

\begin{abstract}
Background : Diabetes Mellitus is a metabolic disease that conciated with lifestyle. Diabetes Mellitus patient with proper diabetes nutrition knowledge and change their dietary pattern will be able to control blood sugar. Persadia ( Persatuan Diabetes Indonesia) is diabetes group wich is expected to have a better in nutrition knowledge, dietary pattern, and blood glucose control

Objective : This research aims were to determine the differences of nutrition knowledge, dietary pattern, and blood glucose control among Persadia members and non members

Method : This study was cross sectional. Subjects were type 2 diabetes mellitus patient in Pantiwilasa Citarum Hospital. Total subjects were 42 people taken by consecutive sampling and divided into 2 groups, Persadia members and non members. The nutrition knowledge is balanced nutrition for diabetes. Nutrition knowledge and dietary pattern measured by questionnaire. Blood glucose control was glucose was determined by HbAlc. Statistical analysis used was Independent t-test and Mann-Whitney

Result : The members Persadia have higher nutrition knowledge $(52,4 \%)$ than non members $(47,6 \%)$ and have better dietary pattern $(38,1 \%)$ than non member (33,3\%). Persadia members also have better blood glucose control $(61,7 \%)$ than non members $(57,1 \%)$. However, level of nutrition knowledge, dietary pattern, and blood glucose control were not difference $(p>0,05)$

Conclusion : There was no difference in nutrition knowledge, dietary pattern, and blood glucose control among member and non members of Persadia.
\end{abstract}

Key word : Diabetes mellitus; nutrition knowledge; dietary pattern; blood glucose control (HbAlc)

\begin{abstract}
ABSTRAK
Latar Belakang : Diabetes Mellitus merupakan penyakit metabolik yang berhubungan dengan gaya hidup. Penyandang DM yang mempunyai pengetahuan gizi yang cukup, dan mengubah pola makannya, dapat menjaga kadar glukosa darahnya tetap terkendali. Persadia (Persatuan Diabetes Indonesia) merupakan sebuah organisasi bagi penyandang DM. Pasien DM yang menjadi anggota Persadia diharapkan memiliki pengetahuan gizi, pola makan dan kontrol glukosa darah yang lebih baik.

Tujuan : Penelitian ini bertujuan untuk mengetahui perbedaan pengetahuan gizi, pola makan, dan kontrol glukosa darah pada anggota Persadia dan non anggota.

Metode : Penelitian ini merupakan penelitian cross sectional. Subjek penelitian adalah pasien diabetes mellitus tipe 2 di RS Pantiwilasa Citarum. Besar subjek penelitian adalah 42 orang yang diambil secara consecutive sampling dan dibagi dalam 2 kelompok yaitu anggota Persadia dan non anggota. Pengetahuan gizi merupakan pengetahuan mengenai gizi seimbang bagi DM. Pola makan merupakan kebiasaan makan yang dikonsumsi sehari-hari. Pengetahuan gizi dan pola makan dinilai melalui kuesioner. Kadar glukosa darah merupakan konsentrasi glukosa darah yang diukur melalui pemeriksaan HbAlc. Analisis statistik yang digunakan adalah Independent t-test dan Mann-Whitney.
\end{abstract}

Hasil : Subjek pada anggota Persadia memiliki presentase pengetahuan gizi baik yang lebih tinggi $(38,1 \%)$ daripada non anggota Persadia (14,3\%) dan memilki pola makan baik yang lebih tinggi $(38,1 \%)$ daripada non anggota Persadia (33,3\%). Anggota Persadia juga memilki kontrol glukosa yang lebih baik (61,7\%) daripada non anggota Persadia (57,1\%). Meskipun begitu tidak ada perbedaan pengetahuan gizi, pola makan dan kontrol glukosa darah pada anggota Persadia dan non anggota $(p>0,05)$

Simpulan : Tidak ada perbedaan pada pengetahuan gizi, pola makan, dan kontrol glukosa darah pada anggota Persadia dan non anggota Persadia

Kata kunci : Diabetes mellitus; pengetahuan gizi; pola makan; kontrol glukosa darah (HbAlc)

\section{PENDAHULUAN}

Diabetes mellitus (DM) adalah penyakit metabolik yang berlangsung kronik progresif, dengan gejala hiperglikemi yang disebabkan oleh gangguan sekresi insulin, gangguan kerja insulin, atau keduanya. ${ }^{1,2,3}$ Data mengenai epidiomiologi penyakit diabetes mellitus telah mengalami peningkatan dari tahun ke tahun. Penelitian 
Askandar Tjokroprawiro menunjukkan jumlah penderita diabetes melitus di dunia dari 110,4 juta pada tahun 1994 melonjak 1,5 kali lipat (175,4 juta) pada tahun 2000 dan melonjak dua kali lipat (239,3 juta) pada tahun $2010 .^{4}$

Diabetes Mellitus merupakan penyakit kronik yang tidak dapat disembuhkan, tetapi sangat potensial untuk dikendalikan melalui pengelolaan DM. Diabetes Mellitus juga merupakan penyakit yang berhubungan dengan gaya hidup, oleh karena itu berhasil tidaknya pengelolaan DM sangat tergantung dari pasien itu sendiri dalam mengendalikan kondisi penyakitnya dengan menjaga kadar glukosa darahnya dapat tetap terkendali. ${ }^{4}$ Dari studi yang pernah dilakukan Miller, pengetahuan responden tentang pengelolaan DM sangat penting untuk mengontrol kadar glukosa darah.

Empat pilar utama pengelolaan DM adalah perencanaan makan, latihan jasmani, obat hipoglikemik, dan edukasi. ${ }^{6}$ Penderita DM yang mempunyai pengetahuan rendah tentang pengelolaan DM berisiko kadar glukosa darahnya tidak terkendali 2,34 kali dibanding dengan responden yang memiliki pengetahuan yang cukup. $^{7}$ Pada penelitian Jazilah menunjukkan bahwa sebanyak $47 \%$ responden mempunyai pengetahuan rendah tentang pengelolaan DM. Dari $47 \%$ responden yang mempunyai pengetahuan rendah $58,1 \%$ diantaranya mempunyai praktik kurang baik terhadap pengelolaan DM, sehingga mempunyai kadar gula darah yang tidak terkendali. ${ }^{7}$ Penderita DM yang mempunyai pengetahuan yang cukup tentang diabetes, akan mengubah perilakunya, sehingga dapat mengendalikan kondisi penyakitnya agar dapat meningkatkan kualitas hidup menjadi lebih baik. ${ }^{8}$

Pengetahuan dapat diberikan melalui edukasi. ${ }^{8}$ Pemberian edukasi dapat diberikan secara personal atau kelompok. Pada penelitian Losen Adnyana yang dilakukan pada pasien rawat jalan RS Sanglah Denpasar yang mendapatkan edukasi mengenai pengelolaan DM secara personal, hanya $37 \%$ yang mengalami perubahan perilaku dalam menjalani diet secara teratur, dan hanya $40 \%$ yang memiliki kontrol gula darah baik. ${ }^{9}$

Tingginya persentase tingkat pengendalian glukosa darah yang buruk menunjukkan masih belum optimalnya pelaksanaan berbagai pilar dari pengelolaan DM seperti edukasi, perencanaan makan, latihan jasmani dan pemakaian Obat Hipoglikemik Oral (OHO) dan insulin secara efektif. Dari penelitian Losen Adnyana menunjukkan masih kurangnya kepatuhan pasien DM yang telah diberikan edukasi secara personal. ${ }^{9}$ Sehingga pengelolaan DM perlu penanganan khusus seperti dibentuknya suatu organisasi bagi para penderita diabetes yang secara kontinyu diberikan penyuluhan yang menerangkan tentang prinsip pengobatan DM yang efektif. Prinsip dari pengelolaan DM pada dasarnya adalah pengaturan pola hidup untuk mempertahankan kondisi fisik maupun metabolik, melalui program-program seperti penyuluhan kesehatan, pengaturan makanan atau diit, kegiatan jasmani atau olah raga, dan konsumsi obat-obat hipoglikemik baik oral maupun suntikan insulin. ${ }^{10}$

Persadia (Persatuan Diabetes Indonesia) adalah sebuah organisasi yang bergerak dalam bidang pelayanan bagi pasien diabetes meliitus di Indonesia. Anggota Persadia terdiri dari dokter, perawat, ahli gizi, pasien diabetes, keluarga pasien diabetes dan orang-orang yang peduli terhadap diabetes. Kegiatan rutin yang dilakukan oleh Persadia adalah pemeriksaan kadar glukosa darah, penyuluhan, pemeriksaan tekanan darah, dan olahraga. Persadia dapat dijadikan sarana dalam pelaksanaan edukasi secara berkelompok.

Persadia adalah organisasi penyandang DM yang dibina oleh Rumah Sakit. Kelebihan Persadia adalah yang memiliki program rutin seperti olahraga dan seminar yang diharapkan dapat memperbaiki gaya hidup penyandang DM. Sampai saat ini belum ada penelitian mengenai pengetahuan, pola makan, dan kontrol glukosa darah pasien DM yang mengikuti Persadia dan diberikan edukasi secara berkelompok. Oleh karena itu penelitian ini secara umum bertujuan untuk mengetahui perbedaan pengetahuan, pola makan, dan kontrol glukosa darah antara anggota Persadia dan non anggota Persadia.

\section{METODE}

Penelitian ini dilaksanakan di RS Pantiwilasa Citarum Semarang pada bulan September 2011 - November 2011. Desain penelitian adalah cross sectional. Subjek penelitian adalah pasien rawat jalan yang menyandang DM tipe 2 di RS Pantiwilasa Citarum baik yang menjadi anggota Persadia dan mengikuti kegiatan di Persadia maupun pasien rawat jalan penyandang DM tipe 2 non anggota Persadia. Besar subjek penelitian adalah 42 orang yang dibagi dalam 2 kelompok, yaitu kelompok penyandang DM yang menjadi anggota Persadia sebanyak 21 orang dan pasien DM yang bukan anggota Persadia yang sebanyak 21 orang. Besar subjek diperoleh melalui 
perhitungan uji hipotesis terhadap rerata dua populasi dengan tingkat kemaknaan 0,05 dan power 0,90. Subjek penelitian diambil secara consecutive sampling.

Kriteria inklusi subjek penelitian non anggota Persadia adalah pasien rawat jalan yang berusia 35-74 tahun yang telah didiagnosa menyandang DM tipe 2 minimal 3 bulan sebelum penelitian, dan mengkonsumsi obat penurun kadar glukosa darah. Kriteria inklusi subjek penelitian anggota Persadia adalah pasien rawat jalan yang berusia 35-74 tahun yang telah didiagnosa menyandang DM tipe 2 minimal 3 bulan sebelum penelitian, mengkonsumsi obat penurun kadar glukosa darah dan aktif mengikuti kegiatan di Persadia RS Pantiwilasa Citarum minimal 3 bulan terakhir.

Data yang dikumpulkan berupa data pengetahuan gizi, pola makan, dan pengukuran glukosa darah subjek. Pengetahuan gizi dan pola makan subjek diperoleh dari pengisian kuesioner pengetahuan gizi dan pola makan, pengukuran glukosa darah subjek melalui pemeriksaan nilai HbA1c subjek di laboratorium $\mathrm{x}$.

Variabel pada penelitian ini adalah pengetahuan gizi, pola makan, dan kontrol glukosa darah. Pengetahuan gizi dan pola makan diperoleh dengan menggunakan kuesioner. Kuesioner pengetahuan gizi berisi 20 soal pertanyaan yang berhubungan dengan diet DM . Total skor adalah 20 , dengan ketentuan nilai 0 , apabila jawaban responden salah; dan nilai 1 , apabila jawabannya benar. Perhitungan total nilai pengetahuan responden adalah :

Total skor pengetahuan $=\frac{\text { Nilai semua jawaban }}{\text { Total skor jawaban }} \times 100 \%$

Setelah dilakukan penghitungan skor, maka hasil dikategorikan, sebagai berikut:

- Kurang < $60 \%$ jawaban benar

- Cukup 60\% - 80\% jawaban benar

- $\quad$ Baik > $80 \%$ jawaban benar

Sedangkan kuesioner pola makan berisi 18 soal dengan nilai berbeda. Untuk soal 1-3 bernilai 4, soal 4-13 bernilai 3, dan soal $14-18$ bernilai 2 . Dengan total nilai adalah 50. Hasil penilaian dikategorikan sebagai berikut :

Total skor pola makan

$=\frac{\text { Nilai semua jawaban }}{\text { Total skor jawaban }} \times 100 \%$

- $\quad$ Tidak berpola makan baik, skor $<80 \%$

- $\quad$ Berpola makan baik, skor $\geq 80 \%$
Hasil total dari penilaian kuesioner pengetahuan dan pola makan dapat digunakan untuk menilai pengetahuan gizi dan pola makan subjek.

HbA1c (hemoglobin terglikasi) merupakan salah satu cara untuk memantau kadar glukosa darah. HbA1c, disebut juga glycohemoglobin, atau disingkat A1c merupakan salah satu pemeriksaan darah yang penting untuk mengevaluasi pengendalian glukosa darah dengan cara menilai status glikemik jangka penjang. ${ }^{12}$ Diabetes yang tidak terkontrol akan mengakibatkan timbulnya komplikasi, untuk itu pada penyandang diabetes kadar HbA1C ditargetkan kurang dari $7 \% .{ }^{13}$ Kontrol glukosa darah merupakan konsentrasi glukosa darah dalam tubuh yang diperiksa dengan pemeriksaan HbA1C untuk menggambarkan status glikemik jangka panjang sebagai indikator paparan kumulatif kadar glukosa darah berlebih selama periode $3-4$ bulan. Data pemeriksaan HbA1C diperoleh melalui pemeriksaan laboratorium yang dilakukan di RS Pantiwilasa Citarum. Kontrol glukosa darah dinyatakan sebagai terkontrol dan tidak terkontrol. American Diabetes Association (ADA) merekomendasikan bahwa kontrol glukosa darah dinyatakan terkontrol jika nilai HbA1C subjek < 7\%, sedangkan glukosa darah tidak terkontrol, nilai $\mathrm{HbA} 1 \mathrm{C}$ adalah $\geq 7 \% .^{14}$

Analisis univariat meliputi jenis kelamin, pendidikan terakhir, pekerjaan, kelompok umur, dan nilai HbA1c. Data pengetahuan gizi, pola makan, dan kontrol glukosa darah pada kelompok anggota Persadia dan non anggota bersifat numerik, sehingga digunakan uji Mann Whitney untuk pola makan karena distribusi data tidak normal, dan uji Independent t-test untuk pengetahuan dan kontrol glukosa darah karena data berdistribusi normal dan memenuhi syarat.

\section{HASIL PENELITIAN}

\section{Gambaran Pasien Rawat Jalan di RS Pantiwilasa Citarum Baik yang Menjadi Anggota Persadia maupun Non Anggota}

Pasien DM baik anggota Persadia maupun non anggota merupakan pasien rawat jalan dari bagian penyakit dalam. Pasien DM baik anggota Persadia maupun non anggota dianjurkan melakukan kontrol rutin satu bulan sekali agar status kesehatan pasien dapat terus dipantau oleh dokter. Pada beberapa pasien yang menderita DM dengan ulkus, kontrol biasanya dilakukan satu minggu sekali untuk pembersihan luka. Mekanisme yang dilakukan saat pemeriksaan rawat jalan untuk pasien DM adalah pemeriksaan laboratorium, penimbangan berat badan, 
pengukuran tekanan darah, dan pemeriksaan oleh dokter. Setelah dilakukan pemeriksaan dokter, pasien DM akan diberikan resep obat penurun kadar glukosa darah untuk dikonsumsi selama satu bulan.

Anggota Persadia di RS Pantiwilasa Citarum mengikuti kegiatan Persadia yang meliputi seminar yang diadakan tiap 6 bulan sekali, senam yang diadakan tiap minggu, dan lomba pada event-event tertentu. Senam bagi anggota Persadia dilakukan tiap hari Kamis dimulai pukul 06.45 dengan durasi selama 30 menit. Persadia melakukan pemeriksaan glukosa darah menggunakan glukometer secara rutin setiap satu bulan sekali.

\section{Karakteristik Subjek Penelitian}

Karateristik subjek yang dilihat berdasarkan jenis kelamin, pendidikan, pekerjaan, dan kelompok umur pada kelompok anggota Persadia dan non anggota ditunjukkan dalam tabel 1 .

Tabel 1. Deskripsi subjek penelitian berdasarkan jenis kelamin, kelompok usia, pendidikan terakhir, dan pekerjaan subjek

\begin{tabular}{lllll}
\hline \multicolumn{1}{c}{ Karakteristik Subjek } & \multicolumn{2}{l}{$\begin{array}{l}\text { Anggota Persadia } \\
(\mathbf{n = 2 1})\end{array}$} & \multicolumn{2}{l}{$\begin{array}{l}\text { Non Anggota } \\
\text { Persadia (n=21) }\end{array}$} \\
\cline { 2 - 5 } & $\mathbf{n}$ & $\mathbf{\%}$ & $\mathbf{N}$ & $\mathbf{\%}$ \\
\hline Jenis Kelamin & 10 & 47,6 & 11 & 52,4 \\
$\quad$ Pria & 11 & 52,4 & 10 & 47,6 \\
$\quad$ Wanita & & & & \\
Kelompok Usia & 1 & 4,8 & 5 & 23,8 \\
35-44 tahun & 3 & 14,3 & 6 & 28,6 \\
45-54 tahun & 6 & 28,5 & 7 & 33,3 \\
55-64 tahun & 11 & 52,4 & 3 & 14,3 \\
65-74 tahun & & & & \\
Pendidikan terakhir & 2 & 9,5 & 4 & 19 \\
SD & 3 & 14,3 & - & - \\
SMP & 10 & 47,6 & 10 & 47,6 \\
SMA & 6 & 28,6 & 1 & 4,8 \\
Akademi & - & & 6 & 28,6 \\
PT & & & & \\
Pekerjaan & 2 & 9,5 & 4 & 19 \\
Tidak bekerja & 8 & 38,1 & 3 & 14,3 \\
Wiraswasta / pedagang & 3 & 14,3 & 9 & 42,9 \\
Swasta & 8 & 38,1 & 1 & 4,8 \\
Pensiunan PNS & - & - & 4 & 19 \\
PNS & & & & \\
\hline
\end{tabular}

Pada tabel 1 terlihat bahwa pada anggota Persadia jumlah subjek wanita lebih besar $(52,4 \%)$ daripada pria $(47,6 \%)$. Sebaliknya, pada non anggota subjek pria lebih besar $(52,4 \%)$ daripada wanita $(47,6 \%)$. Anggota kelompok Persadia mayoritas $(52,4 \%)$ berumur 65-74 tahun sedangkan pada kelompok non anggota, subjek penelitian tersebar merata pada semua kelompok umur.
Pendidikan subjek penelitian baik anggota Persadia maupun non anggota sebagian besar adalah berpendidikan menengah atau SMA dan sederajatnya (47,6\%). Pekerjaan anggota kelompok Persadia mayoritas adalah wiraswasta dan pensiunan PNS $(38,1 \%)$, sedangkan non anggota mayoritas adalah pekerja swasta $(42,9 \%)$. 
Tabel 2. Deskripsi subjek penelitian berdasarkan pengetahuan gizi, pola makan, dan nilai kontrol glukosa darah subjek

\begin{tabular}{|c|c|c|c|c|}
\hline \multirow[t]{2}{*}{ Variabel } & \multicolumn{2}{|c|}{$\begin{array}{l}\text { Anggota } \\
\text { Persadia } \\
(\mathrm{n}=21)\end{array}$} & \multicolumn{2}{|c|}{$\begin{array}{l}\text { Non Anggota } \\
\text { Persadia }(n=21)\end{array}$} \\
\hline & $\mathbf{n}$ & $\%$ & $\mathbf{n}$ & $\%$ \\
\hline \multicolumn{5}{|l|}{ Pengetahuan Gizi } \\
\hline Kurang $\quad$ (nilai $<60 \%)$ & 2 & 9,5 & 8 & 38,1 \\
\hline Cukup (nilai $60 \%-80 \%$ ) & 11 & 52,4 & 10 & 47,6 \\
\hline Baik $\quad($ nilai $>80 \%)$ & 8 & 38,1 & 3 & 14,3 \\
\hline \multicolumn{5}{|l|}{ Pola Makan } \\
\hline Tidak berpola makan baik $(<80 \%)$ & 13 & 61,9 & 14 & 66,7 \\
\hline Berpola makan baik $\quad(\geq 80 \%)$ & 8 & 38,1 & 7 & 33,3 \\
\hline \multicolumn{5}{|l|}{ Kontrol Glukosa Darah } \\
\hline Terkontrol & 13 & 61,9 & 12 & 57,1 \\
\hline Tidak terkontrol & 8 & 38,1 & 9 & 42,9 \\
\hline
\end{tabular}

Pada tabel 2 dapat dilihat bahwa pengetahuan anggota Persadia maupun non anggota mayoritas adalah cukup, $(52,4 \%)$ pada anggota Persadia dan $(47,6 \%)$ pada non anggota. Pola makan responden baik anggota Persadia maupun non anggota mayoritas tidak berpola makan baik $(61,9 \%)$ pada anggota Persadia dan $(66,7 \%)$ pada non anggota. Kontrol glukosa darah baik pada anggota Persadia maupun non anggota mayoritas adalah terkontrol, sebanyak $(61,9 \%)$ pada anggota Persadia dan $(57,1 \%)$ pada non anggota.

Tabel 3. Uji beda Pengetahuan Gizi, Pola Makan, dan Kontrol Glukosa Darah pada Kelompok Anggota Persadia Dan Non Anggota

\begin{tabular}{llllll}
\hline \multirow{2}{*}{ Jenis Pengukuran } & \multicolumn{4}{l}{$\begin{array}{l}\text { Anggota Persadia } \\
(\mathrm{n}=21)\end{array}$} & \multicolumn{3}{l}{$\begin{array}{l}\text { Non Anggota } \\
\text { Persadia }(\mathrm{n}=21)\end{array}$} & $\mathrm{p}$ \\
\cline { 2 - 6 } & Rerata & SD & Rerata & SD & \\
\hline Nilai pengetahuan gizi & 72,6 & 15,7 & 61,9 & 15,7 & $0,952^{\mathrm{a}}$ \\
Nilai pola makan & 73,8 & 11,4 & 74,2 & 10,7 & \\
Nilai HbA1c & 7,1 & 1,4 & 6,4 & & 0,6 \\
& & & & & $67^{\mathrm{b}}$ \\
& & & & & $0,347^{\mathrm{a}}$ \\
\hline
\end{tabular}

Ket: ${ }^{\text {a }}$ Uji Independent t-test

${ }^{\mathrm{b}}$ Uji Mann-Whitney

Pada tabel 3 terlihat bahwa rerata nilai pengetahuan gizi pada anggota Persadia lebih tinggi $(72,6)$ daripada non anggota $(61,9)$. Hal sebalikanya terlihat pada rerata nilai pola makan dan nilai HbA1C. Rerata nilai pola makan anggota Persadia justru lebih rendah $(73,8)$, dibandingkan non anggota $(74,2)$. Demikian juga rerata nilai HbA1C anggota Persadia juga lebih tinggi $(7,1 \%)$ daripada non anggota $(6,4 \%)$.

Tabel 3 juga menggambarkan uji beda pengetahuan gizi, pola makan, dan kontrol glukosa darah pada anggota Persadia dan non anggota. Hasil uji menunjukkan tidak ada perbedaan bermakna pada pengetahuan gizi, pola makan, dan kontrol glukosa darah pada anggota Persadia dan non anggota Persadia $(\mathrm{p}>0,05)$.

\section{PEMBAHASAN \\ Karakteristik Sampel}

Subjek penelitian di RS Pantiwilasa Citarum sebagian besar $(33,3 \%)$ berusia lanjut, yaitu 65-74 tahun. Sekitar 50\% lansia usia $\geq 65$ tahun mengalami intoleransi glukosa dengan kadar gula darah puasa normal. ${ }^{15}$ Diabetes pada usia lanjut berbeda secara metabolik dengan diabetes pada kelompok usia lainnya, sehingga diperlukan pendekatan terapi yang berbeda pada kelompok usia ini. Sangat penting bagi penyandang DM untuk memperhatikan pengelolaan DM secara 
tepat seperti pemantauan kadar glukosa secara teratur dan pengaturan pola makan untuk menjaga agar kadar glukosa darah tetap terkendali terutama pada usia lanjut.

Pendidikan bukan merupakan faktor penentu tingkat pengetahuan seseorang namun pendidikan yang cukup membantu menentukan tingkat kemampuan seseorang untuk memahami edukasi mengenai gizi yang diberikan. ${ }^{16}$ Dari hasil analisis yang dilakukan pendidikan terakhir sampel baik anggota Persadia maupun non anggota sebagian besar $(47,6 \%)$ adalah SMA. Namun, berdasarkan hasil penelitian jumlah anggota Persadia yang memilki nilai pengetahuan gizi baik lebih banyak $(38,1 \%)$ daripada non anggota $(14,3 \%)$. Hal ini dapat disebabkan oleh karena tingkat pengetahuan dapat dipengaruhi oleh faktor internal dan faktor eksternal. Faktor internal meliputi pendidikan, pekerjaan, dan umur, sedangkan faktor eksternal adalah lingkungan, sosial budaya, ${ }^{17}$ pengalaman, dan informasi yang didapatkan melalui edukasi. Edukasi dapat diperoleh melalui beberapa sumber informasi, diantarnya dari tenaga kesehatan. ${ }^{18}$

\section{Perbedaan Pengetahuan Gizi Antara Anggota Persadia dan Non Anggota}

Uji statistik menunjukkan bahwa tidak terdapat perbedaan yang bermakna pada pengetahuan gizi antara anggota Persadia dan non anggota Persadia ( $\mathrm{p}=0,952)$. Seharusnya ada perbedaan pengetahuan gizi antara anggota Persadia dan non anggota, hal ini disebabkan karena Persadia memiliki program peningkatan pengetahuan gizi untuk anggotanya berupa kegiatan yang diadakan satu kali dalam 6 bulan. Program tersebut ternyata belum cukup efektif dalam meningkatkan pengetahuan gizi DM para anggotanya.

Peningkatan pengetahuan gizi tidak berasal dari pendidikan formal saja, tetapi juga diperoleh dari pendidikan non formal. ${ }^{19,21}$ Peningkatan pengetahuan gizi melalui pendidikan non formal dapat diperoleh dari pengalaman, seminar kesehatan, media massa, media cetak dan media elektronik, maupun pemberian edukasi oleh dokter, ahli gizi maupun tenaga kesehatan lainnya. ${ }^{19}$ Penyampaian edukasi melalui seminar di Persadia kemungkinan kurang dapat diterima secara efektif untuk para anggota. Edukasi yang diberikan hendaknya dilakukan secara bertahap dengan cara ceramah, diskusi, sharing sesama anggota Persadia yang lebih banyak melibatkan penyandang DM juga keluarga, dan diulang-ulang serta dilakukan review sebelum berlanjut ke pembahasan berikutnya sehingga dapat diingat dan mudah diterima oleh anggota. Adanya booklet yang menjadi pegangan bagi anggota juga berpengaruh sehingga edukasi tidak hanya berlangsung pada saat bertatap muka tetapi dapat dilakukan mandiri oleh anggota Persadia.

\section{Perbedaan Pola Makan Anggota Persadia dan Non Anggota}

Pada penyandang diabetes bentuk dari perubahan perilaku bermula dari meningkatnya pengetahuan mengenai pengelolaan diabetes, kemudian sikap untuk bersedia mendengarkan atau melihat informasi mengenai gizi, mengikutsertakan kebiasaan diet atau pola makan yang baru dalam gaya hidupnya, dukungan kelompok dan keluarga, serta penyuluhan gizi yang berkelanjutan sangat berpengaruh terhadap perubahan perilaku seseorang dalam berperilaku sesuai dengan pola hidup sehat. ${ }^{21}$ Berdasarkan uji statistik tidak terdapat perbedaan pada pola makan antara anggota Persadia dan non anggota Persadia $(\mathrm{p}=$ $0,677)$.

Pengetahuan gizi baik yang dimiliki anggota Persadia masih belum dapat menjadikan pola makan anggota Persadia menjadi baik. Baik anggota Persadia maupun non anggota mayoritas tidak berpola makan baik, $(61,9 \%)$ anggota Persadia, dan $(66,7 \%)$ pada non anggota. Hasil kuesioner pola makan pada subjek baik anggota maupun non anggota menunjukkan sebagian besar subjek masih mengkonsumsi makanan gorengan sebagai lauk dengan alasan lebih cepat dan praktis. Mereka menyatakan bahwa memang masih sulit menghindari makanan gorengan, begitu pula untuk makanan selingan, beberapa subjek masih memilih gorengan ataupun kue manis sebagai camilan dibandingkan buah ataupun kacang-kacangan. Selain itu beberapa subjek masih ada yang jadwal makannya tidak teratur, yaitu dengan melewatkan sarapan pagi. Meskipun memiliki pengetahuan gizi baik tetapi tidak timbul kesadaran dalam dirinya untuk mengubah perilaku makannya maka pola makannya tidak akan berubah menjadi baik. Sehingga perilaku seseorang untuk taat menjalani diet atau kepatuhan terhadap diet dapat berhubungan dengan intensitas pemberian penyuluhan, edukasi dan motivasi yang diberikan secara teratur dan terus menerus, tingkat ekonomi dan kesadaran dalam diri individu tersebut.

Pemberian motivasi oleh lingkungan terdekat mampu memberikan dampak positif bagi perilaku dan pola konsumsi penyandang DM. Pada anggota Persadia misalnya, motivasi dapat diperoleh dari sesama anggotanya saat diadakan 
pertemuan. Namun saat penelitian dilakukan, kegiatan saling memotivasi sesama anggota tersebut belum pernah dilakukan. Padahal saat berkumpul bersama para anggota Persadia dapat berdiskusi tentang pengalaman dan segala hal mengenai DM, termasuk juga saling memotivasi sesama anggotanya, sehingga akan timbul kesadaran dalam diri para nggota Persadia untuk dapat patuh terhadap diet DM.

\section{Perbedaan Kontrol Glukosa Darah Anggota Persadia dan Non Angoota}

Hasil pemeriksaan HbAlc memberikan gambaran rata-rata gula darah selama periode waktu 6-12 minggu, sehingga pemeriksaan $\mathrm{HbA1c}$ dapat digunakan sebagai kontrol glukosa darah selama 3 bulan terakhir bagi penyandang DM. HbA1c juga dapat digunakan untuk mencerminkan pola makan penyandang DM selama 3 bulan sebelum pemeriksaan. Dari hasil uji statistik tidak terdapat perbedaan nilai $\mathrm{HbA1C}$ antara anggota Persadia dan non anggota Persadia $(\mathrm{p}=0,347)$.

Subjek pada kelompok anggota Persadia yang memiliki rerata nilai HbA1c anggota Persaadia lebih tinggi $(7,1 \%)$ dibanding non anggota $(6,4 \%)$. Hal ini dapat disebabkan karena salah satu faktor yang dapat mempengaruhi kontrol glukosa darah diantaranya adalah usia. Semakin tua usia seseorang maka risiko peningkatan kadar glukosa darah dan gangguan toleransi glukosa semakin tinggi. Subjek penelitian anggota Persadia sebagian besar $(52,3 \%)$ masuk dalam kelompok usia 65-74 tahun, sedangkan non anggota hanya sebanyak (14,2\%). Jumlah subjek pada anggota Persadia yang masuk dalam kelompok usia 65-74 tahun tersebut dapat mempengaruhi nilai $\mathrm{HbA1c}$ subjek dengan kadar glukosa darah tidak terkontrol. ${ }^{22,23}$

Selain usia, pola makan subjek, meliputi jenis, jumlah, dan jadwal makanan yang dikonsumsi juga mempengaruhi nilai HbA1c. Pada anggota Persadia, setelah usai melakukan kegiatan olahraga biasanyan mengkonsumsi makanan ringan sebagai snack. Konsumsi camilan dapat mempengaruhi glukosa darah anggota Persadia. Pada penelitian yang dilakukan oleh Achmad Yoga mengatakan bahwa pola makan yang tidak baik berisiko 4 kali tidak berhasil dalam pengelolaan DM. Dari hasil penelitian, pola makan subjek sebagian besar adalah tidak berpola makan baik $(61,9 \%)$ pada anggota Persadia, sedangkan non anggota sebanyak $(66,7 \%)$. Pola makan yang tidak baik mengakibatkan glukosa darah tidak terkontrol. Hal ini sejalan dengan hasil-hasil penelitian sebelumnya. Penelitian Pi Spunyer dkk, sebagaimana dikutip Achmad Yoga menunjukkan bahwa pasien DM tipe 2 yang melakukan perencanaan diet DM dengan komposisi seimbang ternyata menunjukkan adanya perbaikan yang signifikan terhadap kadar glukosa plasma puasa, HbA1c, indeks massa tubuh dan kolesterol. ${ }^{20}$

\section{SIMPULAN}

Presentase subjek yang memiliki pengetahuan gizi baik pada anggota Persadia lebih banyak $(38,1 \%)$ daripada non anggota $(14,3 \%)$. Presentase subjek yang memiliki pola makan baik pada anggota Persadia lebih tinggi $(38,1 \%)$ dari pada non anggota $(33,3 \%)$. Selain itu, presentase subjek anggota Persadia yang memiliki glukosa darah terkontrol juga lebih tinggi (61,9\%) dibandingkan dengan non anggota $(57,1 \%)$. Hasil uji statistic menunjukkan tidak terdapat perbedaan pada pengetahuan gizi, pola makan dan kontrol glukosa darah pada anggota Persadia dan non anggota Persadia $(\mathrm{p}>0,05)$.

\section{SARAN}

Edukasi dan perencanaan makan merupakan beberapa bentuk pilar pengelolaan bagi penyandang DM. Pengelolaan diabetes perlu dilakukan oleh penyandang DM agar glukosa darahnya terkontrol dan mengurangi resiko terjadinya komplikasi. Persadia sebagai organisasi bagi penyandang DM diharapkan lebih memperhatikan program - program yang perlu dilakukan untuk mendukung pengelolaan diabetes seperti program pemantauan kepatuhan diet dan pola makan, melalui pemberian kuesioner pengetahuan gizi dan pola makan yang dilakukan tiap bulan. Pemantauan kontrol gkukosa darah, melalui pemeriksaan HbA1c secara rutin 3 bulan sekali juga perlu dilakukan Persadia untuk para anggotanya. Serta dilakukannya evaluasi terhadap program-program yang telah dijalankan, agar dapat diketahui apakah program-program tersebut dapat diterima, dipahami, dan telah diaplikasikan dengan baik oleh para anggotanya.

\section{DAFTAR PUSTAKA}

1. Sudoyo Aru W, Bambang Setiyohadi, Idrus Alwi, Marcellus Simadibrata K, Siti Setiati, ed. Ilmu Penyakit Dalam Jilid III Edisi IV. Jakarta: Pusat Penerbitan Ilmu Penyakit Dalam Fakultas Kedokteran Universitas Indonesia. 2006.

2. Darmono, Tony Suhartono, Tjokorda G D Pemayun, et al. Naskah Lengkap Diabetes Melitus Ditinjau dari Berbagai Aspek Penyakit Dalam. Semarang: Badan Penerbit Universitas Diponegoro. 2007. 
3. Wild S, Roglic G, Green A, sicree R, King H. Global prevalence of diabetes. Estimates for the year 2000 and projections for 2030. Diabetes Care 2004; 27: 1218-1224.

4. Tjokroprawiro, Askandar. Hidup Sehat dan Bahagia Bersama Diabetes Melitus. Jakarta: Penerbit PT Gramedia Pustaka Utama. 2006.

5. Miller CK, Edwards L, Kissling G, Sanville L. Nutrition Education Improves Metabolic Outcomes Among Older Adults With Diabetes Mellitus: Result From a Randomized Control Trial Preventive Medicine 2002.

6. Sarwono W. Diabetes Mellitus: Mekanisme Dasar dan Pengelolaannya yang Rasional dalam: Penatalaksanaan Diabetes Melituss Terpadu. Jakarta: FKUI; 2002. p.31-40

7. Jazilah, Paulus Wijono, Toto Sudargo. Hubungan Tingkat Pengetahuan, Sikap dan Prektik (PSP) Penderita Diabetes Mellitus Mengenai Pengelolaan Diabetes Mellitus dengan Kendali Kadar Glukosa Darah. Yogyakarta: Universitas Gajah Mada; 2003.

8. Archer SL, Greenlund KJ, Rith-Najarian S, Croft J, Casper ML. Association of Diabetes Education with Dietary Intake and Biochemical Parameters: the Inter-Tribal Health Project. Journal of the American Dietetic Association; 2002.

9. Losen Adnyana, Hensen, Anak Agung Gde Budhiarta. Penatalaksanaan Pasien Diabetes Melitus di Poliklinik Rumah Sakit Sanglah Denpasar. Dalam Journal Penyakit Dalam Volume 7 Nomor 3. 2006. Tersedia URL: http://ejournal.unud.ac.id/files/pdf/23062011.

10. Kirkman, MS., Williams SR., Caffrey HH., Marrero DG. Impact of a program to improve adherence to diabetes guidelines by primary care physicians. Diabetes Care. 2002.

11. Soeharlina. Perbedaan Pengetahuan Diet dan Asupan Makan Sebelum dan Setelah Mendapat Konsultasi Gizi Pada Pasien Diabetes Mellitus di RS. Dr. Moewardi Surakarta. Politeknik Kesehatan Semarang Jurusan Gizi. 2006.

12. Yulianti Kusniyah, Nursiswati, Urip Rahayu. Hubungan Tingkat Self Care Dengan Tingkat Hba1c Pada Klien Diabetes Melitus Tipe 2 Di Poliklinik Endokrin RSUP Dr. Hasan Sadikin Bandung. 2010; 1-23

13. Kilpatrick, E. S. HbA1c Meassurement. Journal Clinical Pathology. 2004; 57: 344-345. Tersedia URL: http://jcp.bmc.com/files.pdf/30/06/2011.

14. American Diabetes Association. Standards of Medical Care In Diabetes 2010. Diabetes Care. 2004; 27: 1761-73.

15. Manaf, Asman. Etiopatofisiologi dan Terapi Rasional pada Diabetes Melitus Tipe 2. Padang: Fakultas Kedokteran Universitas Andalas. 2009. Tersedia URL: http://repository.unand.ac.id/files.pdf/11/072011
16. Ucik Witasari, Setyaningrum Rahmawaty, Siti Zulaekah. Hubungan Tingkat Pengetahuan, Asupan Karbohidrat Dan Serat Dengan Pengendalian Kadar Glukosa Darah Pada Penderita Diabetes Melitus Tipe 2. Jurnal Penelitian Sains \& Teknologi, Vol. 10, No. 2; 2009.

17. Soegondo, Sidartawan. Diabetes Melitus Sebagai Faktor Risiko Utama Penyakit Kardiovaskular. Pendidikan Kedokteran Berkelanjutan Ikatan Dokter Indonesia. 2006.

18. Nuryani, Sri. Gambaran Pengetahuan dan Perilaku Pengelolaan Penyakit Diabetes Melitus di Puskesmas Parit H.Husni II Pontianak bTahun 2011. Artikel Ilmiah. Pnntianak: Universitas Tanjungpura. 2012.

19. A Wawan, Dewi M. Teori dan Pengukuran Pengetahuan, Sikap, dan perilaku Manusia. Yogyakarta: Nuha Medika; 2010.

20. Achmad Y. Hubungan Antara 4 Pilar Pengelolaan DM dengan Keberhasilan Pengelolaan DM Tipe 2. Artikel Ilmiah. Semarang: Universitas Diponegoro. 2011.

21. Soegondo, Sidartawan, Pradana Soewondo, Imam Subekti, ed. Penatalaksanaan Diabetes Melitus Terpadu. Jakarta: Balai Penerbit FKUI; 2004.

22. Marfu'ah, Dewi K. Perbedaan Perubahan Berat Badan, Aktifitas Fisik, dan Kontrol Glukosa Darah antara Anggota Organisasi Penyandang Diabetes Mellitus dengan non Anggota. Artikel Ilmiah. Semarang: Universitas Diponegoro. 2011.

23. American Diabetes Association. A1C Level and Future Risk of Diabetes: A Systematic Review. Diabetes Care; 2010. 33:1665-1673 